\title{
Multiple chemical sensitivity (MCS): women's health issue
}

\author{
L. Roncati ${ }^{1, *}$, M. Vadalà ${ }^{1}$, C. Laurino ${ }^{1}$, B. Palmieri ${ }^{1}$ \\ ${ }^{1}$ University Hospital of Modena, Modena (Italy)
}

\begin{abstract}
Summary
Multiple chemical sensitivity (MCS) is a controversial, complex, and recurring chronic disturbance resulting from olfactory exposure at low levels to foreign chemicals usually tolerated in the rest of the healthy population, without functional tests capable to explain signs and symptoms of the disorder. Recently, some authors have supported that organic abnormalities in the olfactory sensors and a hyperactive limbic system, combined with peculiar personality traits, can best explain MCS. Epidemiological observations suggest that MCS has a 2-3\% prevalence in the general population and that women are more significantly at risk to develop the disturbance; about $80 \%$ of affected patients are in fact women between the ages of 30 and 50. On closer inspection, many women present with hyperosmia during two other common female conditions, i.e. pregnancy and menstrual migraine, both accompanied by well known neurovegetative limbic symptoms; therefore, it appears reasonable to include a hormonal imbalance in the pathogenesis of MCS.
\end{abstract}

Key words: Multiple chemical sensitivity (MCS); Hyperosmia; Olfactory bulb; Limbic system; Women's health.

Multiple chemical sensitivity (MCS), or idiopathic environmental intolerance, is a controversial, complex, and recurring chronic disturbance resulting from olfactory exposure at low levels to foreign chemicals usually tolerated in the rest of the healthy population, without functional tests capable to explain signs and symptoms of the disorder [1]. According to the World Health Organization (WHO), MCS resembles electromagnetic hypersensitivity, because it is characterized by nonspecific symptoms devoid of apparent toxicological or physiological basis and independent verification [2]. Among the chemical triggers there are: scented products, cleaning agents, pesticides, molds, formaldehyde, vehicle exhaust, synthetic fabrics, plastics, latex, secondhand tobacco smoke, wood smoke, fresh ink, paint fumes, chlorine and fluoride in drinking water, new carpeting, and new furniture [3-9].

Symptoms range from mild to severe and include hyperosmia, rhinitis, weakness, headache, dizziness, anxiety, insomnia, amnesia, nausea, vomiting, pyrosis, diarrhea, rash, itch, muscle pain, joint discomfort, and nerve complaint [10]. In this regard, it has been reported that the inhalation of hydrocarbons can cause hyperosmia, most likely due to the destruction of dopaminergic olfactory neurons [11]. Often a concomitant food intolerance is reported, like celiac disease, gluten sensitivity or lactose intolerance [10].

Historically, MCS was proposed as a distinct entity by the American allergist Theron Randolph (1906 - 1995) in the 1950s; in the years to follow, an association with fibromyalgia, chronic fatigue syndrome, sick building syndrome, Gulf War syndrome, and post-traumatic stress disorder was noticed, with which it seems to share an immune dysfunction and biochemical alterations due to elevated nitric oxide/peroxynitrite mechanism, at the basis of the symptomatology $[12,13]$. It has been pro- posed to group these disturbances into the category of "subjective health complaints", while some authors consider them the expression of a masked depression or, directly, a somatoform disorder [14, 15]. However, polymorphisms in genes involved with chemicals metabolism, such as cytochrome P450 2D6 (CYP2D6), N-acetyltransferase 1 (NAT1), N-acetyl-transferase 2 (NAT2), paraoxonase 1 (PON1), paraoxonase 2 (PON2), and methylenetetrahydrofolate reductase (MTHFR), have been advanced to interpret the different susceptibility to them [16]. Moreover, two recent reviews have suggested that organic abnormalities in the olfactory sensors and a hyperactive limbic system, combined with peculiar personality traits, can best explain MCS $[17,18]$.

The limbic system (from the Latin limbus - border), also known as paleomammalian cortex, is in fact a primordial system of neuronal circuits that control fundamental functions of the individual, such as olfaction, behavior, emotion, and memory [19]. In practice, it represents the brain area where the subcortical structures interact with the cerebral cortex, in order to ensure the integration between the autonomic nervous system and the neuroendocrine one [20]. From this, it is clear that an alteration in the olfactory bulb or inside the limbic system triggers a neurovegetative response (Figure 1). Epidemiological observations suggest that MCS, even if underestimated, has a 2$3 \%$ prevalence in the general population and that women are more significantly at risk to develop the disturbance: about $80 \%$ of affected patients are in fact women aged 30 50 at time of diagnosis [21]. Is it therefore reasonable to include hormonal imbalance in the pathogenesis of MCS? On closer inspection, many women present with hyperosmia during two other common female conditions, i.e. pregnancy and menstrual migraine, both accompanied by well
Clin. Exp. Obstet. Gynecol. - ISSN: 0390-6663 XLVII, n. 5, 2020

doi: $10.31083 /$ j.ceog.2020.05.5127
This is an open access article under the CC BY 4.0 license (https://creativecommons.org/licenses/by/4.0/). 


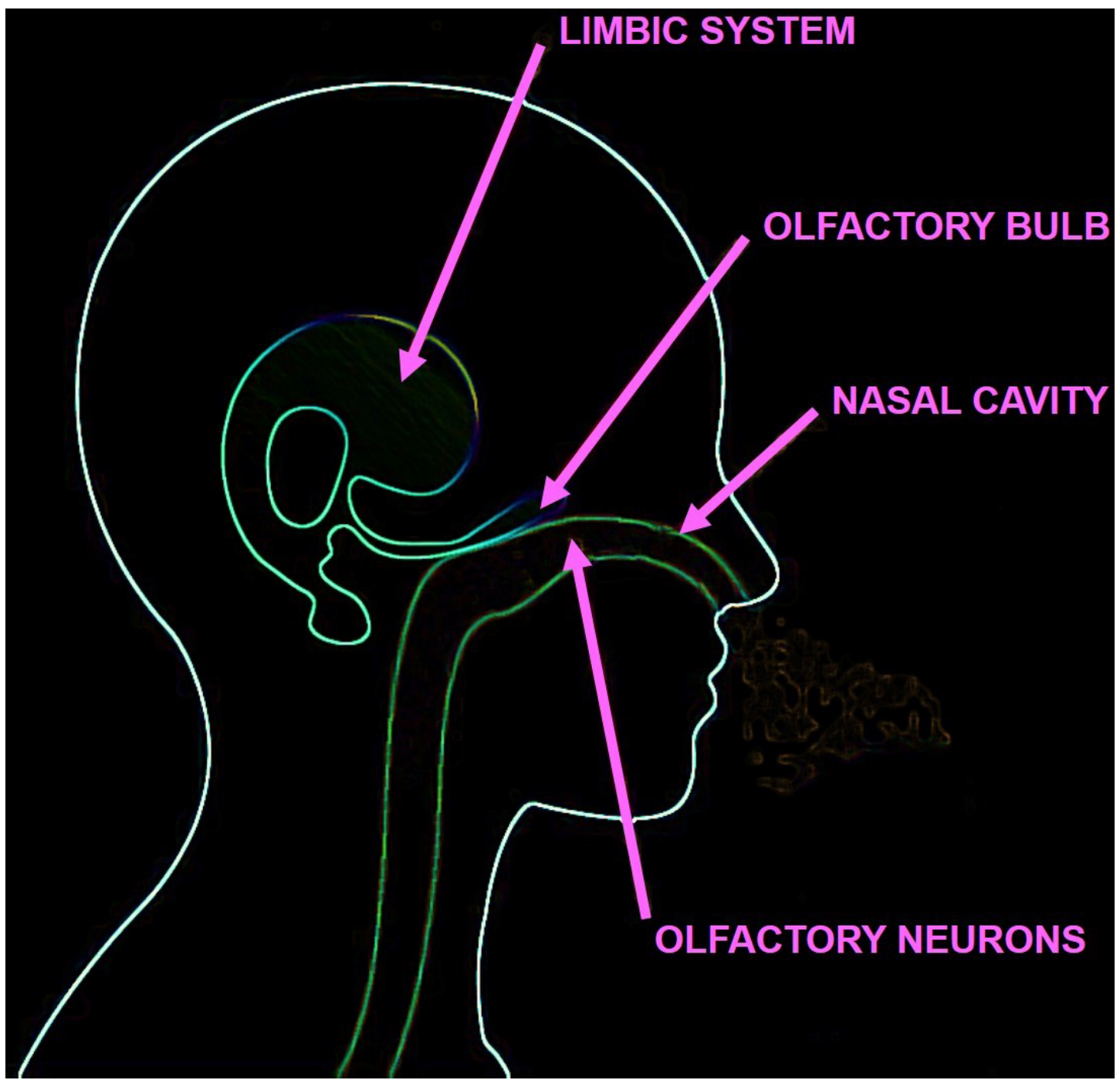

Figure 1. - Anatomical scheme depicting the sites of the alleged targets in MCS genesis and their interconnections: the olfactory neurons in the nasal cavity, the olfactory bulb, and the limbic system.

known neurovegetative symptoms [22, 23]. The assumption of methotrexate in patients with a history of migraine has also been associated with the appearance of hyperosmia [24]. In 2018, the first Italian conference on MCS was held in Modena, during which the international state of the art, future prospects of medicolegal accreditation, and therapy were addressed [25]. Today, MCS diagnosis is still a diagnosis of exclusion and the therapy is mainly based on antihistamine drugs and antidepressants, together with the avoidance of the triggering substances. In the modern era of P4 (predictive, preventive, personalized, and participatory) medicine, the aforementioned Italian event represents the first step towards a deeper knowledge of MCS and of its integrated therapeutic approach.

\section{Acknowledgments}

The authors gratefully acknowledge Mrs. Claudia Boni and Mrs. Manuela Bottazzi for their kind assistance.

\section{Conflict of Interest}

The authors declare no conflict of interest.

Submitted: January 17, 2019

Accepted: March 12, 2019

Published: October 15, 2020

\section{References}

[1] Ministero della Salute: "Sindrome da sensibilità chimica multipla". Available at: http://www.salute.gov.it/portale/temi/p2 6.jsp?lingua $=$ italiano\&id $=4405 \&$ area $=$ indor $\&$ menu $=$ vuoto [In Italian]

[2] World Health Organization: "Electromagnetic hypersensitivity. Available at: https:/www.who.int/peh-emf/publications/facts/ fs296/en/

[3] Magill M.K., Suruda A.: "Multiple chemical sensitivity syndrome". Am. Fam. Physician., 1998, 58, 721.

[4] Roncati L., Manenti A., Roncati M., Vergari B., Maiorana A., Barbolini G.: "Lethal cardiotoxicity from quaternary ammonium compounds contained in an unguarded household detergent at a psychiatric facility". Forensic. Sci. Int., 2017, 278, 19.

[5] Roncati L., Pusiol T., Piscioli F., Lavezzi A.M.: "Neurodevelop- 
mental disorders and pesticide exposure: the northeastern Italian experience". Arch. Toxicol., 2017, 91, 603.

[6] Roncati L., Barbolini G., Scacchetti A.T., Busani S., Maiorana A.: "Unexpected death: anaphylactic intraoperative death due to Thymoglobulin carbohydrate excipient". Forensic. Sci. Int., 2013, 228, 28.

[7] Lavezzi A.M., Ferrero S., Roncati L., Piscioli F., Matturri L., Pusio T.: "Nicotinic receptor abnormalities in the cerebellar cortex of sudden unexplained fetal and infant death victims-possible correlation with maternal smoking". ASN Neuro., 2017, 9, 1759091417720582.

[8] Roncati L., Piscioli F., Pusiol T.: "The endocrine disrupting chemicals as possible stillbirth contributors". Am. J. Obstet. Gynecol., 2016, 215, 532

[9] Roncati L., Piscioli F., Pusiol T.: "The endocrine disruptors among the environmental risk factors for stillbirth". Sci. Total Environ., 2016, 563-564, 1086.

[10] Ross P.M., Whysner J., Covello V.T., Kuschner M., Rifkind A.B., Sedler M.J., et al.: "Olfaction and symptoms in the multiple chemical sensitivities syndrome". Prev. Med., 1999, 28, 467.

[11] Henkin R.I.: "Hyperosmia and depression following exposure to toxic vapors". JAMA, 1990, 264, 2803

[12] Pall M.L., Satterlee J.D.: "Elevated nitric oxide/peroxynitrite mechanism for the common etiology of multiple chemical sensitivity, chronic fatigue syndrome, and posttraumatic stress disorder". Ann. N. Y. Acad. Sci., 2001, 933, 323.

[13] Roncati L., Gatti A.M., Pusiol T., Barbolini G., Maiorana A.: "Acquired immunodeficiency similar to Gulf War illness in a dead former serviceman". J. R. Army Med. Corps., 2015, 161, 153.

[14] Eriksen H.R., Ursin H.: "Subjective health complaints, sensitization, and sustained cognitive activation (stress)". J. Psychosom. Res., 2004, 56, 445

[15] Bailer J., Witthöft M., Paul C., Bayerl C., Rist F.: "Evidence for overlap between idiopathic environmental intolerance and somatoform disorders". Psychosom. Med., 2005, 67, 921.

[16] McKeown-Eyssen G., Baines C., Cole D.E., Riley N., Tyndale R.F. Marshall L., Jazmaji V.: "Case-control study of genotypes in multiple chemical sensitivity: CYP2D6, NAT1, NAT2, PON1, PON2 and MTHFR". Int. J. Epidemiol., 2004, 33, 971.

[17] Rossi S., Pitidis A.: "Multiple chemical sensitivity: review of the state of the art in epidemiology, diagnosis, and future perspectives". J. Occup. Environ. Med., 2018, 60, 138.
[18] Viziano A., Micarelli A., Pasquantonio G., Della-Morte D., Alessandrini M.: "Perspectives on multisensory perception disruption in idiopathic environmental intolerance: a systematic review". Int. Arch. Occup. Environ. Health, 2018, 91, 923.

[19] Morgane P.J., Galler J.R., Mokler D.J.: "A review of systems and networks of the limbic forebrain/limbic midbrain". Prog. Neurobiol., 2005, 75, 143.

[20] Lavezzi A.M., Ferrero S., Roncati L., Matturri L., Pusiol T.: "Impaired orexin receptor expression in the Kölliker-Fuse nucleus in sudden infant death syndrome: possible involvement of this nucleus in arousal pathophysiology". Neurol. Res., 2016, 38, 706 .

[21] Donnay A.H.: "On the recognition of multiple chemical sensitivity in medical literature and government policy". Int. J. Toxicol., 1999, $18,383$.

[22] Cameron E.L.: "Pregnancy and olfaction: a review". Front. Psychol., 2014, 5, 67 .

[23] Sjöstrand C., Savic I., Laudon-Meyer E., Hillert L., Lodin K., Waldenlind E.: "Migraine and olfactory stimuli". Curr. Pain Headache Rep., 2010, 14, 244.

[24] Zargari O.: "Methotrexate, hyperosmia, and migraine". Dermatol. Online J., 2006, 12, 28

[25] $1^{\circ}$ Convegno Nazionale sulla Sensibilità Chimica Multipla: "Sensibilità Chimica Multipla: stato dell'arte internazionale, future prospettive di accreditamento medico-legale e terapia". Available at: https://www.sensibilitachimicamultipla.com/ [In Italian]

Corresponding Author:

L. RONCATI, M.D., Ph.D

Department of Maternal, Infant and Adult Medical and Surgical Sciences,

Institute of Pathology University Hospital of

Modena, Policlinico

Viale del Pozzo, 71

I-41124 Modena (MO), (Italy)

e-mail:emailmedical@gmail.com

roncati.luca@aou.mo.it 